Article

\title{
Urbanism and Geographic Crises: A Micro-Simulation Lens on Beirut
}

\author{
Ali Termos ${ }^{1}$ and Neil Yorke-Smith ${ }^{2, *}$ \\ ${ }^{1}$ Department of Finance, American University in Bulgaria, Bulgaria \\ ${ }^{2}$ Faculty of Electrical Engineering, Mathematics and Computer Science, Delft University of Technology, The Netherlands \\ * Corresponding author (n.yorke-smith@tudelft.nl)
}

Submitted: 16 July 2021 | Accepted: 17 January 2022 | Published: 23 February 2022

\begin{abstract}
At a geographical and strategic confluence, the ancient city of Beirut, Lebanon, has witnessed crises from natural and human causes over the centuries. The modern urban and peri-urban development is a result of neo-classical economics, laissez-faire regulations, and complex socio-political structures. This article considers the contemporary housing situation and asks about its resilience to crises. The methodological approach is speculative simulation. We capture the urban status quo through agent-based simulation, and simulate a range of independent shocks. Although the goal of the article is exploratory and not historical replay, the shocks considered are historical exemplars, such as the explosion on August 4th, 2020. Looking across peri-urban Beirut, we measure qualitative effects on housing economics and dynamics. The research question thus addressed is to determine the optimal amount of capital needed for regeneration without triggering a price increase in the housing market. The contribution of the article is a data-and-modelling approach to humane questions of interest to urban scholars. The simulation model is available open source to provoke further enquiry.
\end{abstract}

\section{Keywords}

agent-based simulation; Beirut; econometrics; exogenous shocks; housing dynamics; urban form

\section{Issue}

This article is part of the issue "Urbanisation, Crisis, and Resilience: The Multiple Dimensions of Urban Transformation in Beirut, Lebanon" edited by Liliane Buccianti-Barakat (Saint Joseph University) and Markus Hesse (University of Luxembourg).

(C) 2022 by the author(s); licensee Cogitatio (Lisbon, Portugal). This article is licensed under a Creative Commons Attribution 4.0 International License (CC BY).

\section{Introduction}

Out of suffering have emerged the strongest souls; the most massive characters are seared with scars. (Kahlil Gibran)

The capital city of Lebanon, Beirut, has witnessed crises from natural and human causes since its founding some 5000 years ago (Mansel, 2010). The city's current urban and peri-urban development is a result of neo-classical economics, laissez-faire regulations, and complex sociopolitical structures (Krijnen \& Fawaz, 2010). The contemporary socio-technical system reflects multiple socioeconomic transitions over time, in line with Hölscher and Frantzeskaki's (2021) theory.

Contemporary urban environments, such as Greater Beirut, manifest themselves as complex, interconnected socio-technical systems. As Termos et al. (2021) note, agent-based models have emerged to complement econometric and social science models in the study of such systems. Agent-based modelling (ABM) is a micro-simulation approach to the study of complex systems. From the local behaviour of the modelled actors, system-level properties emerge. ABM has found wide application in fields from anthropology and economics to biology and linguistics (Van Dam et al., 2013). Heppenstall et al. (2021) summarise the "enormous promise" of ABM for dynamic spatial simulation, including for the geographical and urban planning fields.

This article brings ABM to bear on the crises of Beirut's history in the 21st century. We draw on the spatially-explicit agent-based simulation model of Termos et al. (2021). Those authors studied migration caused by the Syrian War and its effect on the housing 
market, segregation, and urban dynamics. We look at shorter-term consequences on residential housing of three events which left indelible reverberations on the city and its built form. In particular, the article's main research question is to determine the optimal amount of capital needed for regeneration without triggering a price increase in the housing market. It is important for a supply-side driven urban development that housing prices remain constant and do not increase with regeneration. Unlike demand-driven housing policies, by encouraging home ownership through subsidies to home buyers, demand for housing rises along with a spike in housing prices (Floetotto et al., 2016).

The contribution of the article is a data-driven quantitative-qualitative modelling approach to humane questions through agent-based simulation. We offer a methodological approach complementary to and triangulating with equation-based quantisation and literaturebased enquiry. Specifically, we provide an approach that informs the choices that planners, policy makers, and humanitarian organisations might have made in response to shocks upon the urban environment, from a socioeconomic perspective. For this purpose we examine three case studies: the 2005 popular uprising which followed the assassination of the Lebanese prime minister in February 2005 (Knudsen \& Kerr, 2012) and the 2006 Israel-Hezbollah War, centred on Lebanon in July-August 2006 (Salamey, 2014); the influx of refugees from 2011 that followed the onset of the Syrian War (Cherri et al., 2016); and the Beirut Port explosion, an accidental blast in August 2020 considered among the largest artificial non-nuclear explosions (Valsamos et al., 2021). Although adopting historical case studies, this article does not address the causes or geo-political context of the case studies, nor deviate from neutrality over political, jurisdictional, or boundary questions.

After recalling the historical background in the next section and then reviewing the literature in Section 3, in Section 4 we present the methodological approach. Simulations examining the three case studies are described in Section 5, accompanied by a discussion. Section 6 concludes the article with an outlook.

\section{Historical Background: A Snapshot}

After 15 years of civil war that ended in 1990, Beirut downtown was destroyed (Fisk, 2002). A landmark of this destruction is a 25-story Holiday Inn hotel still standing with its bullet-riddled exterior as a witness to a vicious war that divided the city into two parts: Western Beirut with predominately Sunni Muslim population and Eastern Beirut with predominately Christian population. The two parts were divided by a demarcation line known as the Green Line, generally stretched from the north of Beirut to the south (Figure 1). Buildings along the Green Line were either severely damaged or destroyed. The neighbourhoods along this line were mostly abandoned and became uninhabitable such that vegetation grew naturally along this line-hence the Green Line. During the war, people started to move to the side of the city where they felt more secure, and the city grew more divided.

Rafik Hariri was the first prime minister after the war: A real-estate billionaire who built a business empire in Saudi Arabia. Hariri was the godfather of the peace treaty that ended the civil war in 1990, known as the Taef Accord, named after the Saudi city where the deal was brokered (for a detailed account on the reasons behind the war and its ramifications, refer to Fisk, 2002).

Hariri was the maestro of a mega-project known as Solidere to rebuild Beirut, perhaps one of the largest urban redevelopment projects undertaken until that time in West Asia. The name Solidere is the French acronym for "The Lebanese Company for the Development and Reconstruction of Beirut Central District." By agreement with the government, which was controlled by Hariri himself, Solidere enjoyed special powers of eminent domain as well as a limited regulatory authority codified in law. Solidere rebuilt Beirut Central District (BCD) and restored it to its initial state with a modern and lavish style. Despite its attractive and aesthetic urbanism, BCD was not inclusive to all segments of the population as it was before the war. The new BCD is now home for luxury brands and high-end shopping plaza with mostly vacant residential units owned by the wealthy Lebanese diaspora and expatriates from oil-rich Arab countries.

It took many years after the war for the Green Line to gradually fade away. With some limitations, citizens of Beirut started to move across neighbourhoods that previously were unthinkable. However, cognitive dissonance remained prevalent in housing and the quarters of Beirut remain identified by the religious-political factions of their respective dominant population.

The housing sector experienced a boom in the mid1990 s with the restoration of damaged dwellings (also outside $B C D$ ) and the building of a new wave of high-rise residential towers. Most of the new urban development took place in the suburbs to accommodate the increasing demand for housing by the middle class. The majority of the Lebanese population lives in urban or sub-urban areas for the lack of job opportunities in the peripheries. According to World Population Review figures, in 2020 around $86 \%$ of the Lebanese population lived in cities, and $50 \%$ lived in the Greater Beirut area (World Population Review, 2022).

The residential real estate market took a new turn in the early 2000s and beyond when commercial banks started to introduce mortgage lending. With interest rates on mortgages subsidized by the Central Bank (Banque du Liban $[B D L]$ ), mortgage lending soared and so did housing prices. All this came to a sudden stop with the assassination of Hariri in February 2005. The Syrian army, which had been present in Lebanon throughout the war time, started a complete withdrawal from Lebanon in April 2005. The Lebanese economy took 
a harder blow once again by the Israel-Hezbollah war in July-August 2006. The continuous bombardment of Beirut suburbs and other targets across Lebanon for 33 days destroyed hundreds of buildings and dis- placed hundreds of thousands of people (Soliman, 2009). Subsequently, and on another wave of reconstruction, housing prices took to a new high in late 2007 and continued to rise until 2015.

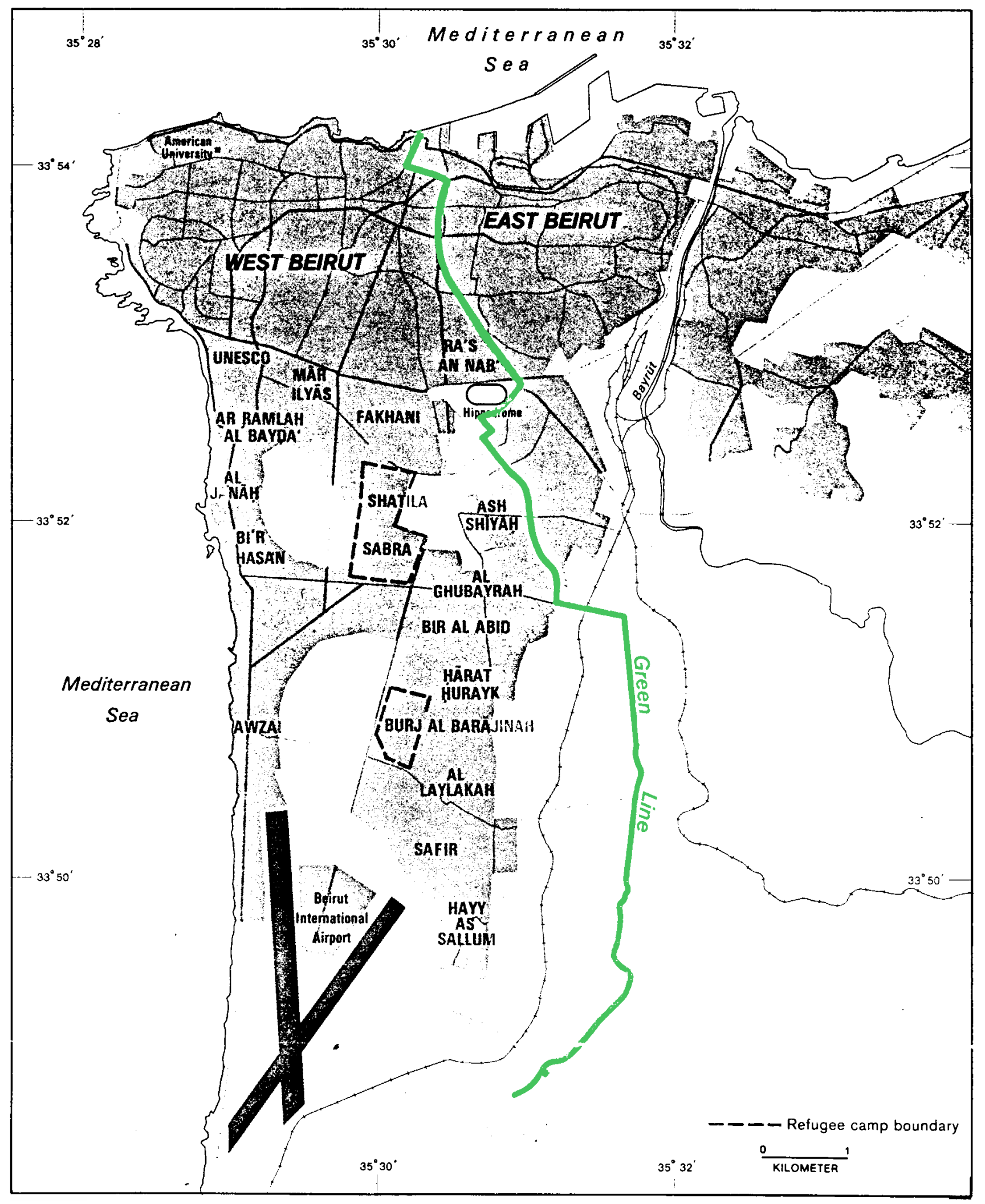

Figure 1. Map of neighbourhoods in Beirut in 1986, which also shows the Green Line. Source: U.S. Central Intelligence Agency in Wikimedia Commons. 
Civil war in Syria broke out in 2011. Scores of Syrians fled their country to Lebanon seeking a safe refuge. By 2014 the number of Syrian refugees in Lebanon reached around 2 million, almost $40 \%$ of the host population. Foreign capital inflow started to dry up and the BDL was under immense pressure to defend the currency peg that had been maintained since 1994 . The fixed peg was brought to an end by the end of 2019 due to chronic corruption and poor policies that led to the drainage of foreign reserves. This was followed by a sharp and continued currency depreciation and rapid economic meltdown hitherto unseen since the 19th century (World Bank, 2021).

\section{Related Work}

Van Dam et al. (2013, p. ix) define an agent as "a representation of a decision-making entity in the real world, be it an individual or an organisation." Then, ABM is "a paradigm for simulating the actions and interactions of autonomous heterogeneous agents, which do not need to be perfectly rational or perfectly informed, in order to study the emergent system-level effects of collective agents' behaviour within a certain environment, over time" (Chappin et al., 2019, p. 322). ABM first of all addresses the question of "What happens when...?" Thus, Van Dam et al. (2013, p. 55) state: "Agent-based models are constructed to discover possible emergent properties from a bottom-up perspective. They attempt to replicate, in silico, certain concepts, actions, relations or mechanisms that are proposed to exist in the real-world, in order to see what happens." This paradigm is complementary to other, historically more common methodologies, such as equation-based modelling (as common in econometrics) and qualitative theories (as common in some social sciences; O'Sullivan \& Haklay, 2000).

As a paradigm of enquiry, ABM came of age in the last decades of the 20th century. Besides many other fields, it is now seen in geography, urban planning, and urban studies. For instance, agent-based models have been exploited to reproduce the evolution of the urban form (Stanilov \& Batty, 2011); to model characteristic urban dynamics, including segregation, gentrification, and informal settlements (Patel et al., 2012; Picascia et al., 2015; Schelling, 1971); to plan urban land use (Ligtenberg et al., 2001; Zidar et al., 2017); to study the housing market (e.g., Yun \& Moon, 2020; Zhang \& Li, 2014), residential search behaviour (Huang et al., 2014), and the sharing economy (Overwater \& Yorke-Smith, 2022); and more broadly in participatory urban planning (Ampatzidou et al., 2018).

Hölscher and Frantzeskaki (2021, p. 1) categorise research about urban transformations into three categories: "in cities" studies "diverse factors, processes and dynamics driving place-based transformations"; "of cities" studies "outcomes of transformative changes in urban (sub-)systems"; and "by cities" studies "changes taking place on global and regional levels as a result of urbanisation and urban development approaches." This article's interest intersects the first two categories.

The notion of transformation is seen in the multilevel perspective (Geels, 2005), which considers sociotechnical transitions in terms of three "levels": innovative practices (niche experiments); structure (the regime); and long-term, exogenous trends (the landscape). The triad for ABM is state, environment, and time (Van Dam et al., 2013); thus multi-level perspective misses time in its analysis, while ABM misses niche. The common between both is environment/landscape and state/regime (we are grateful to an anonymous reviewer for pointing out this connection).

Soliman (2021) identifies how Lebanon is an archetypal example of "urban informality," and connects the multi-layers of formal and informal with socio-technical transformation, particularly with sustainable transition processes-which are crucial in a crisis-ridden region.

As fitting a historic city at the crossroads of trade, Beirut is well-known in the literature (Kassir, 2010; Knudsen \& Kerr, 2012; Mansel, 2010). As narrated in Section 2, notable post-independence events include the Lebanese Civil War, the Cedar Revolution, conflicts with Israel, the Syrian War "spillover" and refugees, and the economic collapse and 2020 port explosion. Krijnen (2018) reviews the post-Lebanese Civil War gentrification. The war and subsequent politics are treated by Fisk (2002) and Salamey (2014). Cherri et al. (2016) and many others study refugees, and Barbarino et al. (2021, p. 1) point out that "the migration-city-nexus has become central in migration and urban studies alike." Bisat et al. (2021) dissect the contemporary Lebanese economic collapse. Srour and Yorke-Smith (2016) apply agent-based simulation to study the Port of Beirut processes. Valsamos et al. (2021) highlight the study of the port explosion with simulation methods.

\section{Methodology}

At a high level, the methodological approach is to study selected historical shocks to the Beirut residential housing market by means of $A B M$ and simulation. To achieve this, we adapt the spatially-explicit ABM of Termos et al. (2021).

\subsection{Model}

The ABM of Termos et al. (2021) models the urban dynamics of residential housing of Beirut. Its original purpose was to study the possible societal consequences and economic indicators of migration, notably the influx of refugees during the 2010s (Cherri et al., 2016). The ABM includes both economic and cultural components. We adopt and extend this model, both conceptually and in implementation.

The economic model adopted in the ABM is the rent gap theory. The concept of the rent gap was introduced 
by noted British geographer Neil Smith: the difference between the actual (current) economic return from land, and the maximum potential return if the land were put to its "highest and best use" (Smith, 1979). Thus, the ABM can observe gentrification effects from the decline and regeneration of properties.

In the ABM, agents represent households. Each household lives at a location in the city, which represents a residential dwelling. Note that more than one household can live at a location, and such apartment blocks are common in Beirut. The agents seek to move if their income permits, if their current dwelling is too poor in maintenance, or if the cognitive dissonance with their neighbours is too great (Portugali, 2011). Locations have a maintenance level representing the condition of the dwelling; it declines in time, and can be repaired or redeveloped; the decline is faster if the location is unoccupied. Agent types are either (Lebanese) citizens or (Syrian) refugees; each agent has an income level. Refugees will tolerate poorer living conditions and denser population, if they have no other option. For details of the model, we refer to Termos et al. (2021) and the references cited therein.

We make the following modifications to the above baseline model:

- Extending the geographic range from the strict boundaries of the municipality to a large portion of peri-urban Beirut. This is important because of the urban sprawl and population percentage outside the municipal boundary, which is relatively small.

Validity: Income, maintenance, and cognitive dissonance can be modelled for Greater Beirut in the same way as for within the municipal boundaries. Indeed, the formal boundary of the city is much smaller than the de facto city, and the urban form is seamless and unabated between the two. Note we do not assume the income (and other attributes) is identical between districts, but rather base it on data: this is equally true for districts within the municipal boundary and those without.

- Including the building density per district. This is important because residential options are not uniform between districts.

Validity: The lack of building density is a valid development of the Termos et al. (2021) model. Indeed, its lack is a deficiency of their original ABM.

- For each case study, calibrating on housing price and population data for the point in time, and removing refugees' influx if prior to the Syrian War.

Validity: It is necessary to calibrate each case study at the relevant month when the case begins. It would be invalid to assume that, e.g., 2011 data is a starting point for a case in 2006. Moreover, since there were no Syrian refugees prior to 2011, of course they cannot be in the simulation prior to that point.

The simulation cycle is one month.

$A$ visualisation of the $A B M$ is seen in Figure 2. The model is implemented in the dedicated ABM language NetLogo (Wilensky, 1999), version 6.2 (base model available at www.doi.org/10.4121/13033154). The model of this article is available at www.doi.org/10.4121/ 18780524.

It is important to recognise that this article demonstrates a data-and-modelling approach on three historical case studies. We provide calibrated models that characterise the historical situations but do not precisely replicate them. This intention has three reasons. First, the ABM provides a stylised but grounded abstraction of the modelled socio-technical system (Edmonds et al., 2019; Van Dam et al., 2013). Second, data of sufficient granularity is simply not available for Lebanon: for example, there has been no population census since 1932 (Maktabi, 1999). Third, the ABM can be validated and prove insightful for planning and policy decisionsand for retrospective analysis - without the overhead of attempting overly-precise replication (Sun et al., 2016).

\subsection{Data}

In order to calibrate the simulation, six items of data are required: geo-locational, demographics, building density, housing prices, property conditions, and (particularly after 2011) refugee population. Data paucity on Lebanon is an ongoing challenge (Faour \& Mhawej, 2014; Government of Lebanon \& UN, 2017). As with the base model, our data acquisition process follows that of Termos et al. (2021). Whereas those authors consider the years 2009-2015 for their analysis, the case studies in this article go back further to 2005 and forward to 2020 . Termos et al. (2021) also did not consider building density because they considered only population-based shocks, not physical or economic shocks; therefore we explain in more detail the process for obtaining this data.

Open-source GIS data came from OpenStreetMap (www.openstreetmap.org/relation/5466662), the Central Administration of Statistics (2022), and Facebook Connectivity Lab and Center for International Earth Science Information Network (2016). We note that OpenStreetMap is crowd-sourced, with the pros and cons of that source.

Population is estimated from UN (population.un. org/wpp), World Bank (databank.worldbank.org/source/ population-estimates-and-projections), and WorldPop (www.worldpop.org). Refugees numbers are estimated from UN High Commissioner for Refugees figures (www. unhcr.org/lebanon.html).

Table 1 gives summary statistics. Note we down-scale the actual number of households to 500 . The reason for this is that we are not attempting a 1-1 scale simulation, 


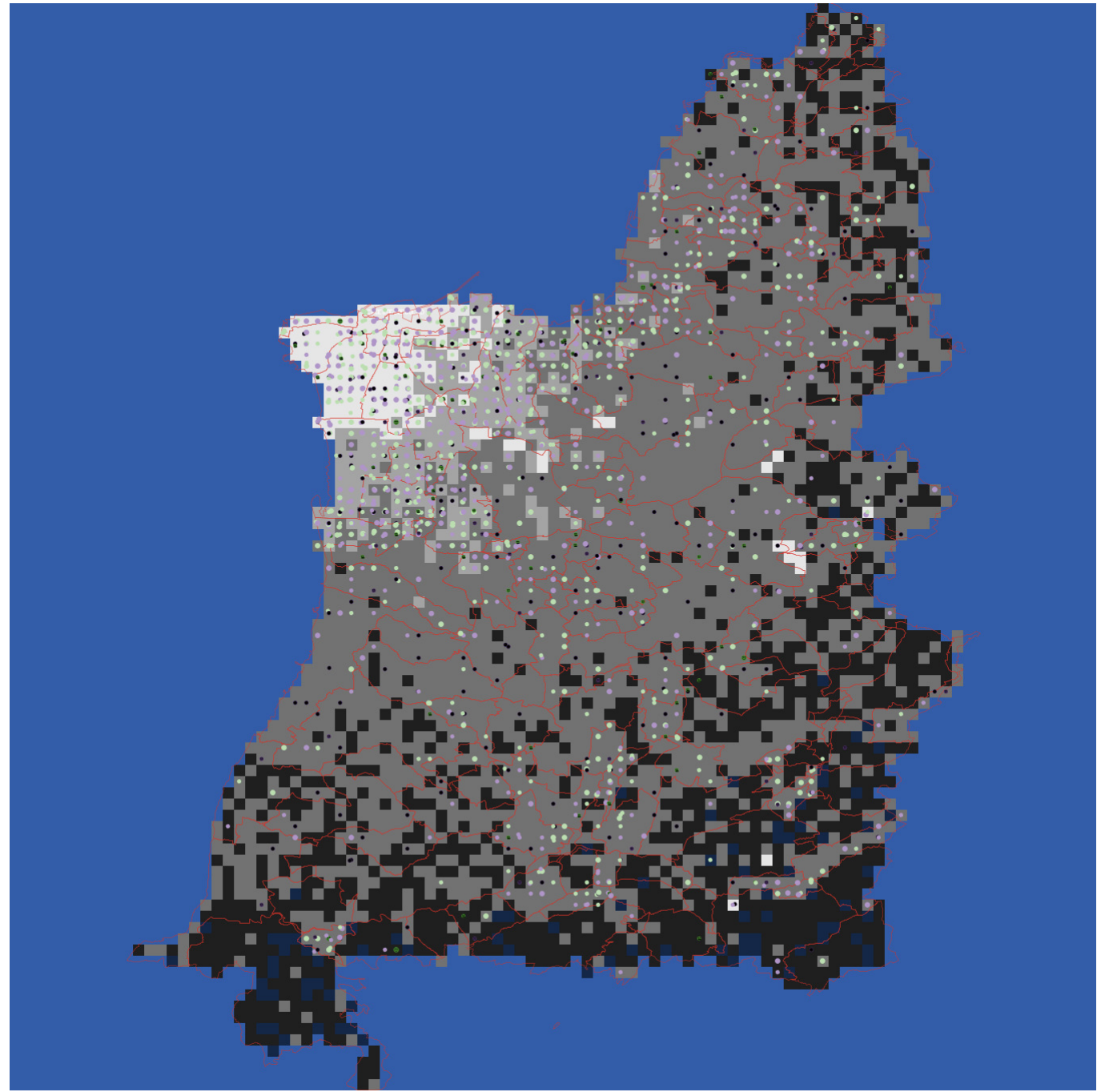

Figure 2. Geographic visualisation of the Greater Beirut region captured in the simulation. Municipal Beirut is seen top left; the Mediterranean Sea borders the west and north. Greater Beirut extends along the coastline and inland (Faour \& Mhawej, 2014); the higher-evaluation area bottom right is relatively less occupied. Squares are coloured by the maintenance level of the properties (brighter = better condition). Household agents are depicted by circles; colour denotes income quartile (bright white $=$ top $25 \%$, bright grey $=$ next $25 \%$, dull grey $=$ next $25 \%$, black = bottom $25 \%$ ). District boundaries are shown by red lines.

nor is it necessary to examine the urban dynamics effects we wish to study. In this regard we follow common practice in ABM. Note that not all agents (circles) are visible in Figure 2, due to emigration and immigration effects. Further, note that more than one agent can reside in a given location (square).

Table 1. Summary statistics of Greater Beirut simulation.

\begin{tabular}{lc}
\hline Quantity & Value \\
\hline Total population & 2.2 million \\
Population density $\left(/ \mathrm{km}^{2}\right)$ & 4,100 \\
Geographic area $\left(\mathrm{km}^{2}\right)$ & 537 \\
Number of districts & 223 \\
Number of households (in simulation) & 500 \\
Number of buildings (in simulation) & 3,879 \\
\hline
\end{tabular}

\subsubsection{Population Density}

First, we identified our target localities using GIS data. Then we matched the coordinates of these target 223 districts with those of the GIS data and computed population in each district, in addition to population of the five nearest points to each district. We then traced population growth for the periods of the events under study, that is, 2005, 2011, and 2020.

\subsubsection{Housing Price}

Termos et al. (2021) developed a housing price index for Lebanon using a partial equilibrium model, a type of econometric approach. To capture the variation in housing price for each district we included another variable to the previous econometric model: the distance from 
each district to downtown Beirut. The hypothesis is that districts closer to the centre have higher housing prices. In the actual urban area, there are exceptions where a more distant district is in fact more affluent than a closer district. We injected knowledge into the model by manually intervening in the most prominent few such outliers. For example, Ouzaii vs. Jounieh and Sin el Fil vs. Baabda. We note that, even if they remain present, the outliers do not affect the results (qualitatively) because they comprise three or four districts out of 223.

Altogether, the econometric model now includes interest rate, building permits, construction cost, in addition to distance. We use the inverse distance for a direct interpretation of the results. For robustness, we replaced building permits with population growth in one iteration. We found that the econometric model with population growth has a better fit (higher R-square); details are provided in Appendix A in the Supplementary Material.

\subsubsection{Building Density and Maintenance Level}

We constructed building density by regressing building permits over population and distance from the centre of downtown Beirut. To compute the maintenance level in 2005 we used a survey from 2017 that was based on expert opinion. Based on that survey we created an instrumental variable by regressing the survey data on house price, population, and distance from the centre. Then we used the regression line to estimate the maintenance levels in 2011 and 2020. In these regressions we created a quadratic equation with an interactive term Price $\times$ Density as one of the explanatory variables in order to capture the nonlinearity of the maintenance level. This allows for maintenance variations that satisfy a matrix with four quadrants as in Table 2.

Appendix A gives further details. We note here that the obtained coefficient on population diminishes from 0.132 in 2005, to 0.112 in 2011, to 0.0969 in 2020, indicating that as population is rising, new building density as proxied by building permits is decreasing but still positive. This is interpreted as being due to limited land available for construction but also reveals that some regeneration is taking place because the coefficient is still positive. For example, while in 2005 a $1 \%$ increase in population leads to $13.2 \%$ more building permits being issued, this figure drops to approximately $9.7 \%$ in 2020 .

\section{Results and Discussion}

With the simulation model and the data in place, we can now proceed to study with our data-driven quantitative- qualitative modelling approach three case studies of 21st century shocks to Beirut. Each case is treated separately, i.e., with a separate instance of the ABM. The parameter values at initialisation were retained the same as Termos et al. (2021). The only exception is that, obviously, the refugee immigration rate was set to zero until simulated time reached 2011.

\subsection{Case 1: Uprising of 2005 and Conflict of 2006}

A nationwide uprising followed the assassination of prime minister Rafik Hariri on 14 February 2005. People flocked to downtown Beirut to protest the murder. The Syrian army had maintained a presence of thousands of troops in Lebanon since the early years of the Lebanese civil war in 1975 (Fisk, 2002). Under the pressure of the non-sectarian protests, the Syrian army withdrew from Lebanon in April 2005. Lebanon entered a period of political turmoil; the assassination fuelled political and sectarian tensions. Increased uncertainty loomed over the future of Lebanon and crippled its economic growth in the months to follow, but later brought a capital influx to a newly "independent" Lebanon from its diaspora.

Amid this heightened political upheaval, a devastating war waged by Israel on Lebanon in July 2006. This war was a blow to Lebanon's economy. It is estimated that the damage to the infrastructure cost at least $\$ 3.5$ billion, 16\% of the GDP (Kotia \& Edu-Afful, 2014). In addition, 15,000 homes were destroyed, and one million people displaced. It took the next five years before the destruction was restored. Soliman $(2004,2009)$ discusses how the displacement from southern Lebanon to Beirut affected the urban fabric of the city.

The impact of the war on Lebanon's economy was multi-faceted. First, there had been already a strain on capital inflow since the Hariri murder a year earlier. The uncertainty that engulfed the investment environment due a series of political and security rundowns slowed down the economic prospects of the country. Second, the displacement of tens of thousands of people who were left homeless by the war added to the government's burden to provide temporary housing for the needy. Housing prices cooled down after the war but started to spike in 2007 and continued to rise well into the year 2015. Third, demand for housing had been strong due to the government programme that provided a generous interest rate subsidy on residential mortgages. Additionally, the BDL offered another subsidy to mortgage lending by allowing commercial banks to use part of their required reserves to sell mortgage loans at an affordable rate. These two programmes together

Table 2. Quadrants of maintenance variations.

\begin{tabular}{llcc}
\hline & & \multicolumn{2}{c}{ Price } \\
\cline { 3 - 4 } & & High & Low \\
\hline \multirow{2}{*}{ Building Density } & High & Medium-high maintenance & Low maintenance \\
& Low & High maintenance & Medium-low maintenance \\
\hline
\end{tabular}


fuelled the demand side of the housing market. With a slower supply of housing, prices soared. The continuous increase in demand combined with easy access to credit created the pretext for a perfect storm: a housing bubble was in the making. This housing bubble came to burst with the economic meltdown which started Autumn 2019 (see Section 5.3).

In the $A B M$ we model the assassination and war as follows:

- An influx of capital and immigration (of diaspora) after 2005;

- Widespread destruction to residential dwellings in the most-affected bombed districts with building conditions set to zero: Chiyah and Haret Hreik;

- Varying damage to residential dwellings in other districts, and a decrease in maintenance level in general (reflecting the collateral and intentional infrastructure damage);

- Household agents who were living in destroyed or badly damaged buildings have to move, and seek another place;

- Influx to Greater Beirut of households displaced from southern Lebanon;

- An increase in the tolerable cognitive dissonance, due to the (forced) mixing of sectarian backgrounds as displaced persons sought shelter;

- Increase in available household mortgage credit ratio;

- Targeted post-war regeneration. Namely, reconstruction of destroyed neighbourhoods, increased lending credit, and an increase in economic capital due to external injections, e.g., from Iran and Qatar.
Details of the model implementation of these are described in Appendix B.

We examine two scenarios in an explorative manner by studying the impact on housing and household mobility for eight years after January 2005: one scenario as if the 2005 and 2006 events did not occur (baseline scenario) and one if they did (Figure 3).

Figure 3 shows that, four years after the 2006 war, the effect is still marked on the most heavilyimpacted areas of Beirut (south of the municipal boundary). In Figure 3 we also see the displaced households spread around the margins of the municipality, in lowercondition dwellings. In the following years, the reconstruction investments and the regular economic cycle lead to regeneration-and refugees from Syria start to arrive (see next subsection). Median house prices are higher in the event scenario (by 55\%), as indeed occurred in the historical data. By considering various scenarios of interest, policy makers might use the $A B M$ to, for instance, examine relative inequality between districts in terms of recovery from the war damage, and ask whether district-specific or general-economic interventions could be better.

\subsection{Case 2: The Syrian War From 2011}

The popular uprisings in 2011 took to the streets of Tunisia, Egypt, Libya, Syria, and Yemen in what came to be known as the Arab Spring. People were demanding a democratic transition from dictatorships that dominated these nations for more than 40 years. In Syria, the uprising failed to bring about a political change but rather seeded a protracted civil war. More than 1.5 million refugees-officially registered with the UN or not-
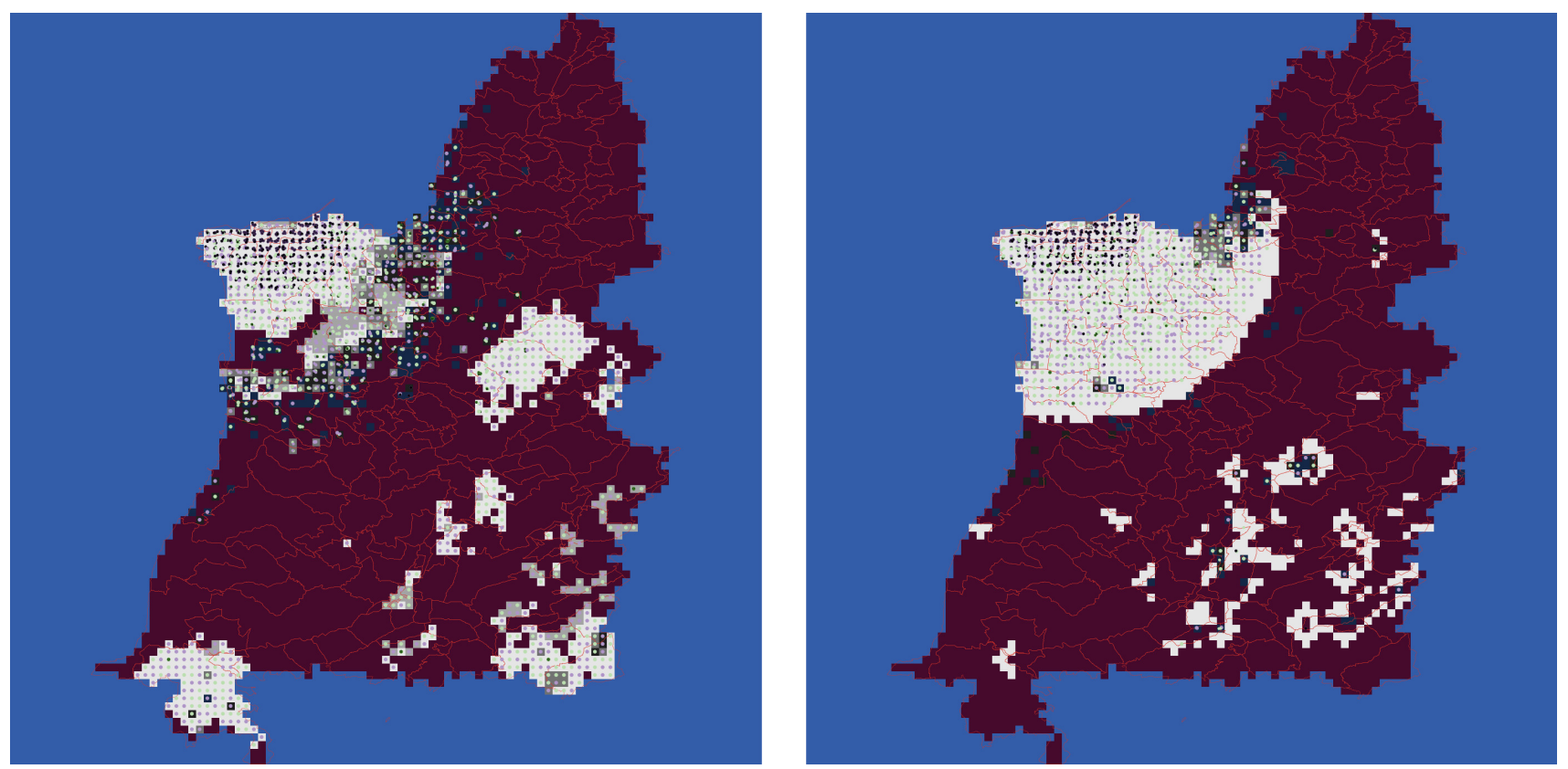

Figure 3. Beirut in 2010, a year prior to the Syrian refugee influx. Scenario with 2005 and 2006 events (left); same time point in the no-events scenario (right). 
fled Syria to seek safe shelters in neighbouring Lebanon. Ten years on, with the war in Syria apparently ending, the majority of the Syrian refugees still reside in Lebanon for various reasons. The significant presence of refugees exerted extreme pressure on the Lebanon's already inadequate infrastructure, especially water supply and electricity power networks. With the collapse of the Lebanese economy in 2020 (see next subsection), added pressure is felt in the energy and food sectors.

The impact of refuges on the urban dynamics of Beirut and its housing market is enormous, as examined in detail in Termos et al. (2021). In the ABM we model the refugee influx from January 2011 with a single change: immigration of large numbers of generally low-income households.

We explore the effects of three refugee scenarios: no influx (baseline), influx during a time window (four years), and ongoing influx. We examine population balance (Lebanese, refugees, "guest" workers, affluent expats), population distribution and mixing, mean household income, mean property price, and maintenance levels. We run the simulation for up to 50 simulated years, to study the longer-term effects. Figure 4, for example, shows mean prices at four time points during the simulation, compared for four different levels of capital in the economy. On the horizontal axis is time at four points in time, measured in time as months from January 2011. On the vertical axis is mean house price in nominal USD. In each graph, at each time-point, prices are shown in four scenarios for parameter "Kapital." This is a simulation parameter of the level of capital in the economy (Picascia et al., 2015).

Higher capital implies more scope for investment and regeneration according to the rent-gap theory. However, we see that higher capital does not necessarily result in higher prices: see both scenarios at month 600, where the highest prices are at lowest levels of capital, as Termos et al. (2021) discuss. We also observe differences between the no-refugee and refugee scenarios: without sufficient capital, the economy cycle in the longer term

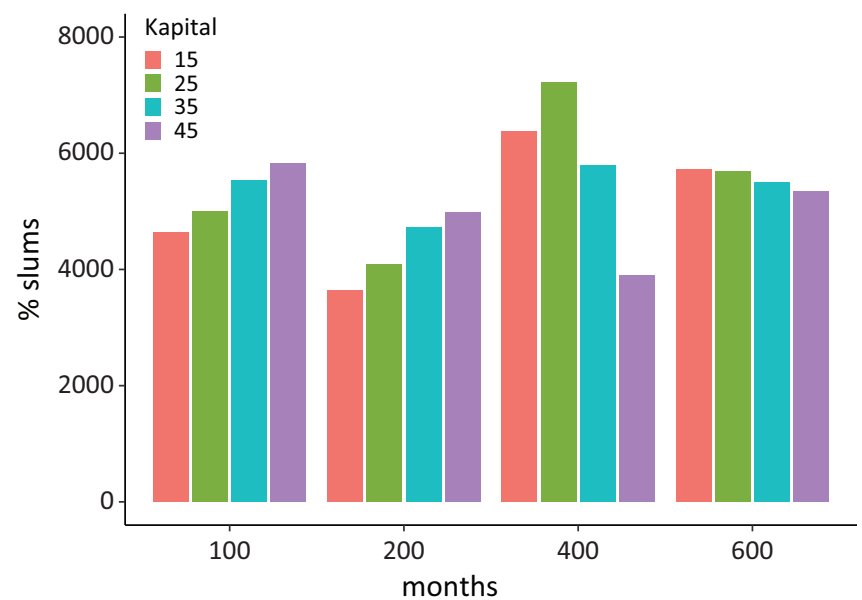

cannot overcome structural deterioration to the housing stock (Termos et al., 2021).

Further, using the $A B M$ we can examine interventions and policy measures that the government or non-government organisations (e.g., World Bank, UN High Commissioner for Refugees) might consider. For instance, changes to the income support granted to UN-registered refugees, or intervention to improve housing conditions.

\subsection{Case 3: Economic Collapse From 2019 and Port Explosion in 2020}

Between 1997 and 2019, the Lebanese Pound (Lira [L.L.]) had been pegged to the U.S. dollar by maintaining an exchange rate of L.L. 1,507 to USD 1 . In the wake of the October 2019 protests against the government, and the consequent economic collapse, this peg came to a halt and the exchange rate of the Lebanese Lira against the dollar depreciated catastrophically to reach a bottom of L.L. 8,000 in July 2020, L.L. 15,000 in March 2021 , L.L. 19,000 in July 2021 , and then L.L. 27,000 in December 2021.

It is estimated that the total banking assets were nearly $\$ 150$ billion by the end of 2019 , three times the value of Lebanon's GDP. Most of these assets had been invested in government bonds through the BDL. Throughout 2020 and up until mid-2021, inflation had risen to $400 \%$, unemployment to $40 \%$, the minimum monthly wage dropped from what was equivalent to $\$ 533$ (nearly L.L. 800,000 ) to $\$ 42$ at an exchange rate of L.L. 19,000 per dollar. According to the World Bank estimates, by July 2021 more than $50 \%$ of the Lebanese population lived under the poverty line. It is also worth noting that there were an estimated 1.3 million Syrian refugees still living in Lebanon, many as formal or informal tenants in Greater Beirut.

In light of the economic collapse and currency depreciation, the impact on the housing market in Lebanon was twofold:

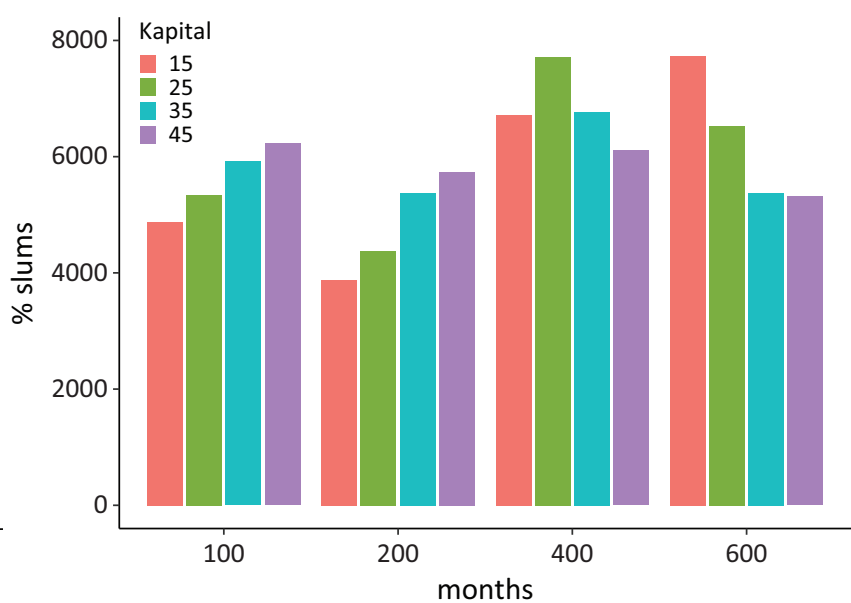

Figure 4. Mean property prices over time according to various levels of capital: no-refugee scenario (left); ongoing refugee immigration scenario (right). Source: Termos et al. (2021, p. 19). 
1) The rental housing market. Given the enormous depreciation in the Lebanese Lira, property owners are assuming sharp declines in the contractual rents they receive in light of the new exchange rate. Given the rise in unemployment and the decline in purchasing power, demand for housing has already dwindled. We expect that this new dynamic in the rental market will further shrink the demand side because in pre-crisis dollar: a rent of $\$ 1,250$ amounts to a third of a middle-class household monthly income (L.L. 6,000,000) but in a post crisis dollar, a rent of $\$ 308$ would eat up the entire monthly income for this group of households, at an exchange rate of L.L. 19,500 per dollar.

2) The home ownership or the mortgage market. A unique dynamic was at play in the mortgage market at the onset of the crisis. The banking sector, being under immense pressure by depositors demanding their deposits, has developed a cheque-clearing market in which the bank pays a depositor a cheque that can be only liquidated to pay a debt of a borrower at either the same bank or at another bank within the country. By this market mechanism, banks managed to reduce their liabilities and mitigate the risk borne by their assets. This has given a rise to demand for real estate in the period that followed the collapse of the banking system and the inception of capital control. Obviously, this unique market irregularity did not clear out all real estate supply. While banks stopped issuing any new loans, particularly real estate mortgages, the mortgage market is stalled. In a market that is hungry for foreign reserves to complete half-finished real estate projects, and in a country where more than $75 \%$ of consumer products are imported, real estate supply has exceeded demand by many folds. The drop in real estate prices was under way by 2021 . According to some estimates, this drop has reached $40 \%$ to $50 \%$ in high-end properties by July 2021.

In the context of the "tragedy in the making" of the economic collapse (Bisat et al., 2021), on 4 August 2020, a huge explosion rocked the entire city of Beirut with reverberations felt as far as Cyprus. It was described as among the largest non-nuclear explosions in modern history (Valsamos et al., 2021). The explosion was a result of detonation of roughly 2,750 tons of ammonium nitrate stored in a warehouse at the Port of Beirut for more than six years. Nearly 200 people were killed and more than 6,000 injured. The force of the blast ravaged the surrounding densely residential areas and commercial districts around the port. The direct loss left 31,000 houses uninhabitable, 13,000 households without shelters, and around 300,000 people displaced (UN Development Programme, 2021). We thank an anonymous reviewer for suggesting that these UN estimates might be true in the immediate time after the explosion, but after the initial cleaning of debris the numbers have been revised downward to around 15,000 damaged homes and 250 completely destroyed.

In the ABM we model the currency crisis and explosion as follows:

- Decrease in household incomes, by an average of $50 \%$;

- Widespread destruction to residential dwellings in the most-affected districts with building conditions set to zero: Marfaa, Medawar, and Remeil;

- Varying damage to residential dwellings in other districts, such as Bachoura, BCD, and Saifeh;

- Household agents who were living in destroyed or badly damaged buildings have to move, and seek another place;

- Increased emigration rate from metropolitan Beirut and Greater Beirut;

- Most damaged areas cannot be regenerated for some time, at least 12 months.

We ran the simulation from a start date of January 2019, for a period of 10 simulated years. In the shorter term, the effect on the city and its residents can be seen (Figure 5). In the longer term, assuming sufficient capital in the economy, the regeneration process means that residents can move back (Figure 6). Note the greater population and population density in the no-explosion scenario.

Quantitative metrics from the simulation show the difference the 2020 events make on urban dynamics, even eight years later (i.e., 2028). In both scenarios (with and without explosion), the percentage of slums-defined as areas with low maintenance level or overcrowding-is substantial. This is due to the decline and economic cycle of the housing market and the continued presence of a large low-income population, both refugees (from Syria) and also Lebanese (due to the currency crisis). However, the explosion scenario has $71 \%$ slums vs. $67 \%$ for the no-explosion scenario. Interestingly, median house prices are higher in the explosion scenario (by 75\%) after eight years (note these nominal figures cannot be compared with those in the other case studies, due to the starting conditions: they are valid internally within each case study). This reflects increased demand for the reduced supply of inhabitable dwellings.

Foreign reconstruction aid, or fiscal aid to the Lebanese public sector, is expected to improve economic conditions. At the time of writing, such aid has been withheld by the international community due to the lack of government in Lebanon. The ABM allows us to explore the what-if effects of such intervention, such as localised regenerations in the east, as seen in Figure 7 (left) and structural aid to the property market (right). Localised regeneration has the advantage of sooner benefitting the residents and condition of the most affected area; 

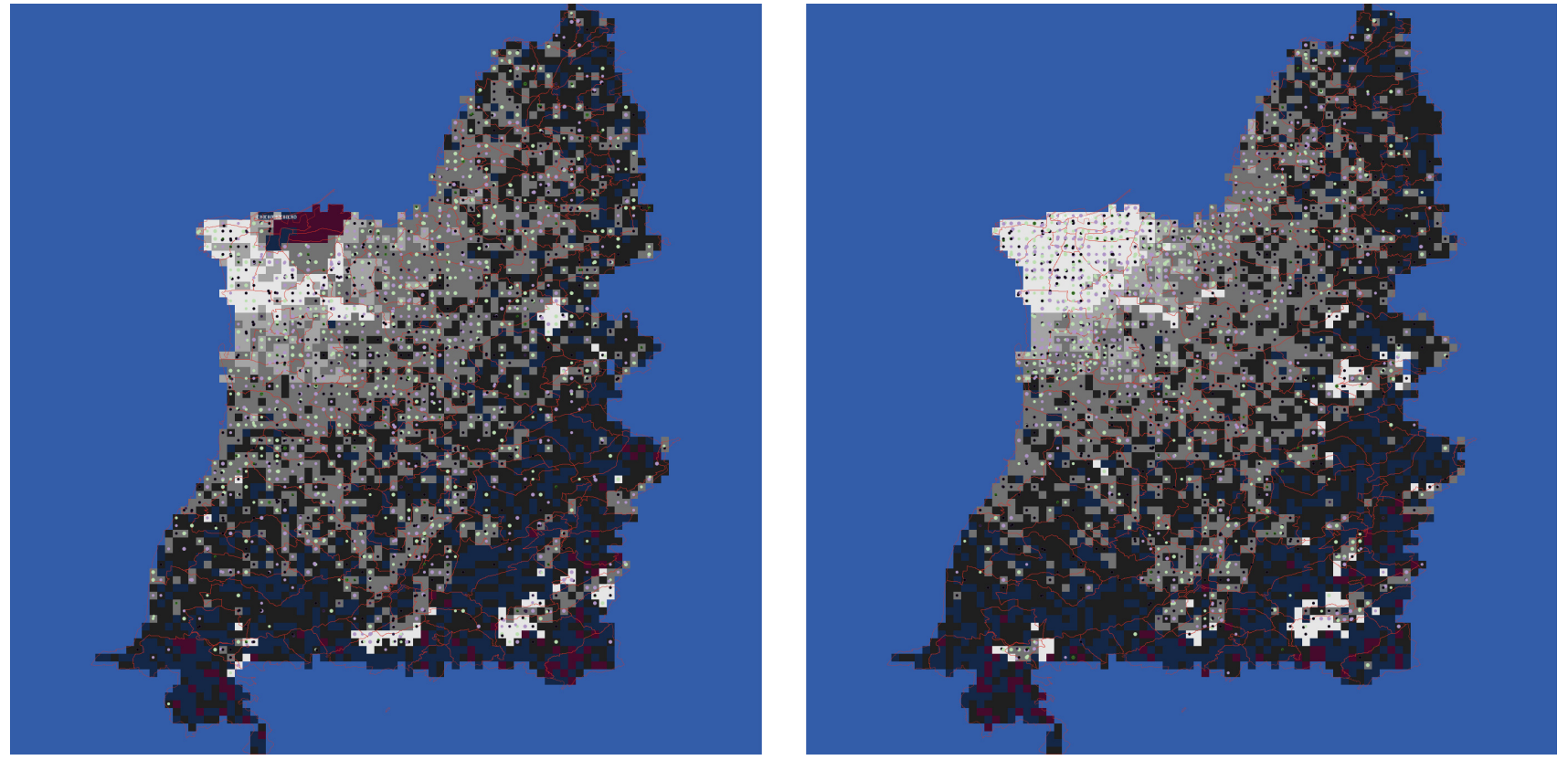

Figure 5. Six months after the explosion (left); same time point in no-explosion scenario (right).
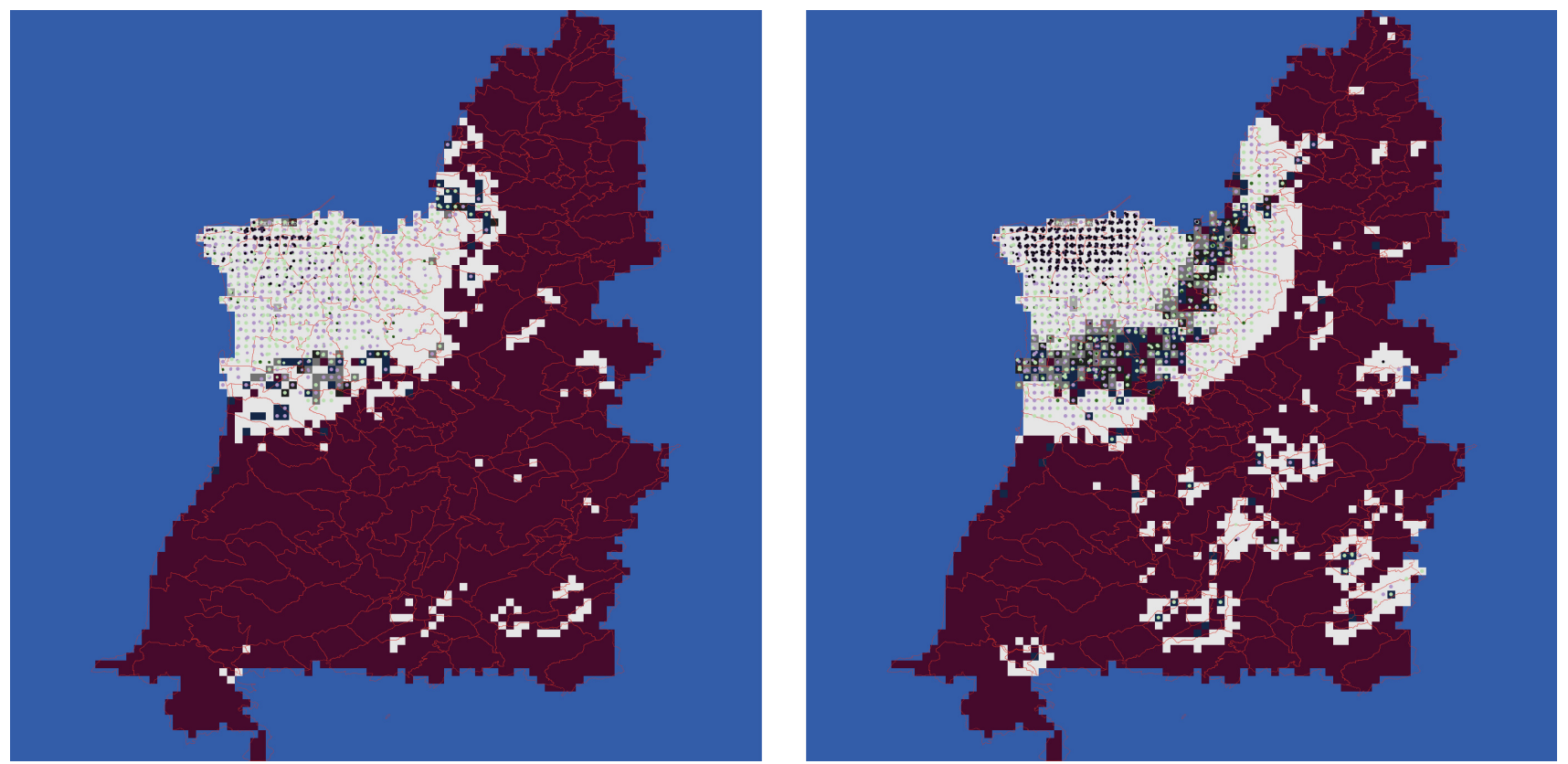

Figure 6. Eight years after the explosion (left); same time point in no-explosion scenario (right).

however, structural aid is more effective overall across the city, and also can regenerate the affected areas after a few years in time.

\section{Conclusions}

This article brings to bear ABM on three of the crises of Beirut's 21st century history. We examined the consequences on the residential housing and urban dynamics of Greater Beirut of a popular anti-government uprising and a border conflict, a spillover of a neighbouring war, and a currency collapse exasperated by a large down- town accidental explosion. The contribution of the article is to show the feasibility of a data-driven quantitativequalitative individual-level simulation, a methodological approach complementary to and triangulating with other methodologies such as equation-based quantisation and literature-based enquiry. Specifically, we studied how ABM can give insights in determining the optimal amount of capital needed for regeneration without triggering a price increase in the housing market. Further, by using the ABM for "what-if" analysis and for understanding emergent urban outcomes, planners, policy makers, and humanitarian organisations 

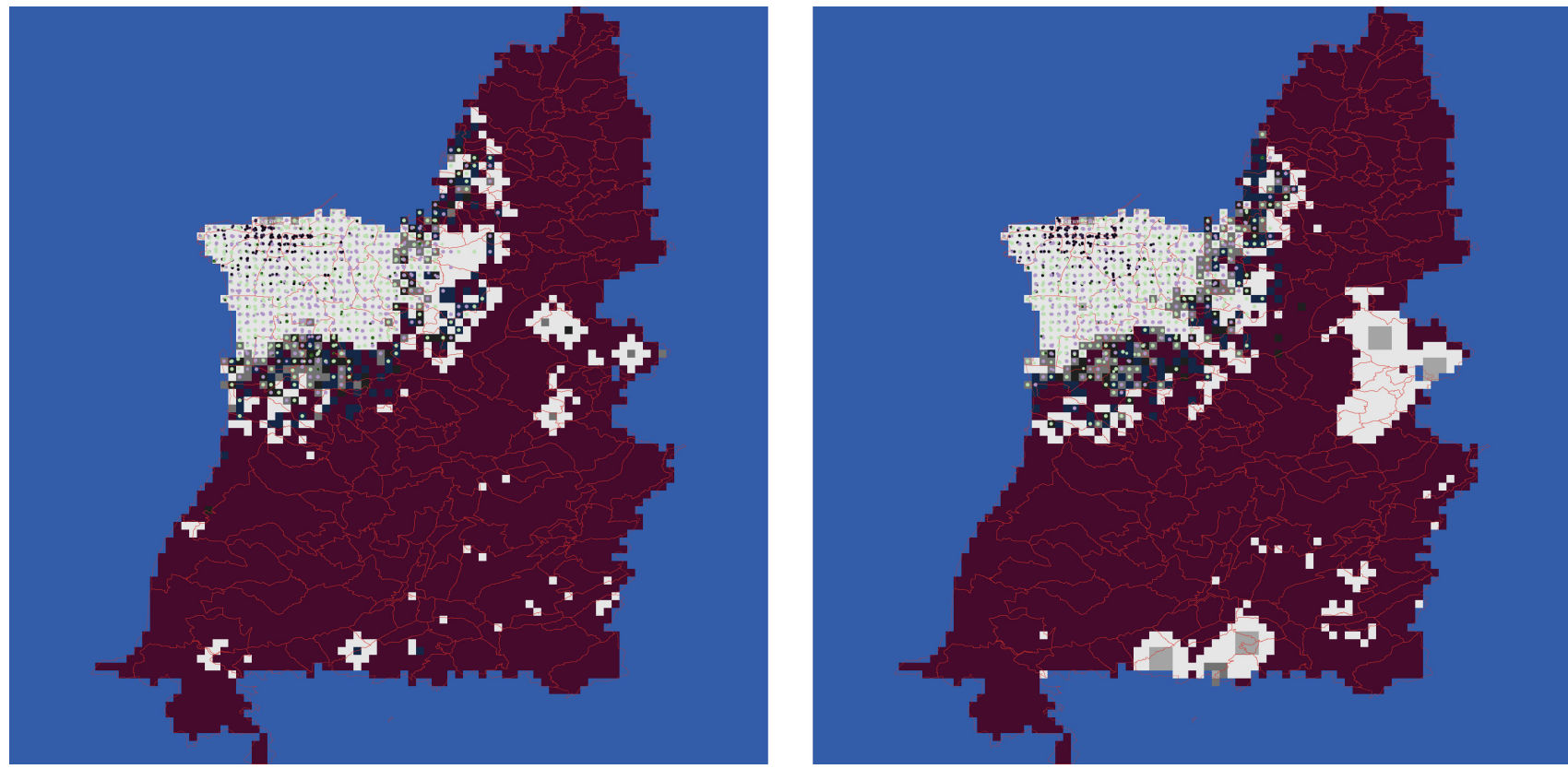

Figure 7. Effect of housing reconstruction aid, seen eight years after the explosion (left); effect of structural aid to the property market seen at same time point (right).

have a tool to help in responding to shocks upon the urban environment.

With the ABM, we can identify the areas and scope of potential built regeneration in Greater Beirut and its periurban area. We see that localised interventions, such as in the area most damaged by the 2020 explosion, appear less important than the general economic situation. We can likewise examine the impact of refugees on the housing market. We see that with sufficient capital in the economy, the shock of large population influxes can be absorbed in the long run. Overall, we can examine the capital-price trade-off in scenarios of interest to policy makers.

It is worth noting how this article enlightens future studies on how one can use GIS data to measure population at the cadastral level or even at the street level and over different periods. This would have not been possible without the use of algorithms to match GIS data with our target localities. In such countries where population census is rare, we bridge this gap by using this technology. Another advantage that is brought about by using (open access) GIS and geo-coded data is that we were able to obtain population counts for the various periods of study or in continuous time if desired; something that is not available with the conventional census data.

A number of expedient directions for future work are opened up by the methodology developed here. We mention two. First, we provided a demonstration of feasibility and potential value of $A B M$ in the study of Beirut's urban dynamics and economy, going beyond prior work that studied only population shocks. One can increase the level of fidelity modelled, bringing together detailed building GIS data with household behaviours. This would blend spatial micro-simulation (cf. Valsamos et al., 2021) with agent-based micro-to-meso simulation. Second, there is a rich vein of macro-economic data analytics that can further inform and complement the ABM: for instance, how Lebanese banks developed non-cash agility in the mortgage market in order to clear out housing supply during the currency crises. This would complement purely econometric analysis of the property market with behavioural aspects from household residential mobility decisions.

\section{Acknowledgments}

The authors thank S. Picascia and the anonymous reviewers. This work was partially supported by TAILOR, a project funded by EU Horizon 2020, Grant No. 952215.

\section{Conflict of Interests}

The authors declare no conflict of interests.

\section{Supplementary Material}

Supplementary material for this article is available online in the format provided by the authors (unedited) and it consists of the appendices. The NetLogo model source code is available online at www.doi.org/ $10.4121 / 18780524$.

\section{References}

Ampatzidou, C., Gugerell, K., Constantinescu, T., Devisch, O., Jauschneg, M., \& Berger, M. (2018). All work and no play? Facilitating serious games and gamified applications in participatory urban planning and gov- 
ernance. Urban Planning, 3(1), 34-46. https://www. doi.org/10.17645/up.v3i1.1261

Barbarino, R., Räuchle, C., \& Scholz, W. (2021). Migrationled institutional change in urban development and planning. Urban Planning, 6(2), 1-6. https://www. doi.org/10.17645/up.v6i2.4356

Bisat, A., Cassard, M., \& Diwan, I. (2021). Lebanon's economic crisis: A tragedy in the making. The Middle East Institute.

Central Administration of Statistics. (2022). Consumer price index. http://cas.gov.lb/index.php/economicstatistics-en/cpi-en

Chappin, E. J. L., Nikolic, I., \& Yorke-Smith, N. (2019). Agent-based modelling of the social dynamics of energy end-use. In M. Lopes, C. H. Antunes, \& K. B. Janda (Eds.), Energy and behaviour: Challenges of a low-carbon future (pp. 321-351). Academic Press.

Cherri, Z., González, P. A., \& Castro Delgado, R. (2016). The Lebanese-Syrian crisis: Impact of influx of Syrian refugees to an already weak state. Risk Management and Healthcare Policy, 2016(9), 165-172.

Edmonds, B., Le Page, C., Bithell, M., Chattoe-Brown, E., Grimm, V., Meyer, R., Montañola-Sales, C., Ormerod, P., Root, H., \& Squazzoni, F. (2019). Different modelling purposes. Journal of Artificial Societies and Social Simulation, 22(3), 6. https://www.doi.org/ 10.18564/jasss.3993

Facebook Connectivity Lab, \& Center for International Earth Science Information Network. (2016). High resolution settlement layer. Center for International Earth Science Information Network. https://ciesin. columbia.edu/data/hrsl

Faour, G., \& Mhawej, M. (2014). Mapping urban transitions in the Greater Beirut area using different space platforms. Land, 3(3), 941-956. https://doi.org/ 10.3390/land3030941

Fisk, R. (2002). Pity the nation: The abduction of Lebanon (2nd ed.). Nation Books.

Floetotto, M., Kirker, M., \& Stroebel, J. (2016). Government intervention in the housing market: Who wins, who loses? Journal of Monetary Economics, 80, 106-123.

Geels, F. W. (2005). The dynamics of transitions in sociotechnical systems: A multi-level analysis of the transition pathway from horse-drawn carriages to automobiles (1860-1930). Technology Analysis \& Strategic Management, 17(4), 445-476. https://www.doi.org/ $10.1080 / 09537320500357319$

Government of Lebanon, \& United Nations. (2017). Lebanon crisis response plan 2017-2020. https:// data2.unhcr.org/en/documents/details/53061

Heppenstall, A., Crooks, A., Malleson, N., Manley, E., Ge, J., \& Batty, M. (2021). Future developments in geographical agent-based models: Challenges and opportunities. Geographical Analysis, 53(1), 76-91. https://www.doi.org/10.1111/gean.12267

Hölscher, K., \& Frantzeskaki, N. (2021). Perspectives on urban transformation research: Transformations in, of, and by cities. Urban Transformations, 3(1), Article 2. https://www.doi.org/10.1186/s42854-02100019-z

Huang, Q., Parker, D. C., Filatova, T., \& Sun, S. (2014). A review of urban residential choice models using agent-based modeling. Environment and Planning $B$ : Planning and Design, 40(4), 1-29.

Kassir, S. (2010). Beirut. University of California Press.

Knudsen, A., \& Kerr, M. (2012). Lebanon after the Cedar Revolution. Hurst.

Kotia, E. W., \& Edu-Afful, F. (2014, June 11). The LebanonIsrael war of 2006: Global effects and its aftermath. Small Wars Journal. https://smallwarsjournal.com/ jrnl/art/the-lebanon-israel-war-of-2006-globaleffects-and-its-aftermath

Krijnen, M. (2018). Beirut and the creation of the rent cap. Urban Geography, 39(7), 1041-1059.

Krijnen, M., \& Fawaz, M. (2010). Exception as the rule: High-end developments in neoliberal Beirut. Built Environment, 36(2), 245-259.

Ligtenberg, A., Bregt, A. K., \& van Lammeren, R. (2001). Multi-actor-based land use modelling: Spatial planning using agents. Landscape and Urban Planning, 56(1), 21-33.

Maktabi, R. (1999). The Lebanese census of 1932 revisited: Who are the Lebanese? British Journal of Middle Eastern Studies, 26(2), 219-241.

Mansel, P. (2010). Levant: Splendour and catastrophe on the Mediterranean. John Murray.

O’Sullivan, D., \& Haklay, M. (2000). Agent-based models and individualism: Is the world agent-based? Environment and Planning A: Economy and Space, 32(8), 1409-1425.

Overwater, A., \& Yorke-Smith, N. (2022). Agent-based simulation of short-term peer-to-peer rentals: Evidence from the Amsterdam housing market. Environment and Planning B: Urban Analytics and City Science, 49(1), 223-240. https://doi.org/10.1177/ 23998083211000747

Patel, A., Crooks, A., \& Koizumi, N. (2012). Slumulation: An agent-based modeling approach to slum formations. Journal of Artificial Societies and Social Simulation, 15(4), Article 2. https://www.doi.org/10.18564/ jasss. 2045

Picascia, S., Edmonds, B., \& Heppenstall, A. (2015). Agent-based exploration of urban economic and cultural dynamics under the rent-gap hypotheses. In F. Grimaldo \& E. Norling (Eds.), Multi-agent-based simulation XV (pp. 213-227). Springer.

Portugali, J. (2011). Revisiting cognitive dissonance and memes-derived urban simulation models. In J. Portugali (Ed.), Complexity, cognition and the city (pp. 315-334). Springer.

Salamey, I. (2014). The government and politics of Lebanon. Routledge.

Schelling, T. C. (1971). Dynamic models of segregation. The Journal of Mathematical Sociology, 1(2), 143-186. 
Smith, N. (1979). Toward a theory of gentrification: A back to the city movement by capital, not people. Journal of the American Planning Association, 45(4), 538-548.

Soliman, A. M. (2004). Regional planning scenarios in South Lebanon: The challenge of rural-urban interactions in the era of liberalization and globalization. Habitat International Journal, 28(3), 385-408.

Soliman, A. M. (2009). Diversity of ethnicity and state involvement on urban informality in Beirut. Journal of Theoretical and Empirical Researches in Urban Management, 3(9), 15-32.

Soliman, A. M. (2021). Urban informality: Experiences and urban sustainability transitions in Middle East cities. Springer.

Srour, F., \& Yorke-Smith, N. (2016). Assessing maritime customs process re-engineering using agent-based simulation. In AAMAS '16: Proceedings of the 2016 International Conference on Autonomous Agents \& Multiagent Systems (pp. 786-795). International Foundation for Autonomous Agents and Multiagent Systems. https://dl.acm.org/doi/10.5555/ 2936924.2937040

Stanilov, K., \& Batty, M. (2011). Exploring the historical determinants of urban growth patterns through cellular automata. Transactions in GIS, 15(3), 253-271.

Sun, Z., Lorscheid, I., Millington, J. D., Lauf, S., Magliocca, N. R., Groeneveld, J., Balbi, S., Nolzen, H., Müller, B., Schulze, J., \& Buchmann, C. M. (2016). Simple or complicated agent-based models? A complicated issue. Environmental Modelling \& Software, 86, 56-67. https://www.doi.org/10.1016/j.envsoft. 2016.09.006

Termos, A., Picascia, S., \& Yorke-Smith, N. (2021). Agentbased simulation of West Asian urban dynamics: Impact of refugees. Journal of Artificial Societies and Social Simulation, 24(1), Article 2. https://www.doi. org/10.18564/jasss.4472
United Nations Development Programme. (2021). Impact of Beirut explosion on economic activities located in the affected neighbourhoods: Socio-economic impact assessment. https://www. arabstates.undp.org/content/rbas/en/home/library/ crisis-response0/impact-of-beirut-explosion-oneconomic-activities-located-in-the.html

Valsamos, G., Larcher, M., \& Casadei, F. (2021). Beirut explosion 2020: A case study for a large-scale urban blast simulation. Safety Science, 137, Article 105190.

Van Dam, K., Nikolic, I., \& Lukszo, Z. (2013). Agent-based modelling of socio-technical systems. Springer.

Wilensky, U. (1999). Home. NetLogo. http://ccl.north western.edu/netlogo

World Bank. (2021, June 1). Lebanon sinking into one of the most severe global crises episodes, amidst deliberate inaction [Press release]. https://www. worldbank.org/en/news/press-release/2021/05/01/ lebanon-sinking-into-one-of-the-most-severe-globalcrises-episodes

World Population Review. (2022). Lebanon. https:// worldpopulationreview.com/countries/lebanonpopulation

Yun, T.-S., \& Moon, I.-C. (2020). Housing market agentbased simulation with loan-to-value and debt-toincome. Journal of Artificial Societies and Social Simulation, 23(4), Article 5. https://www.doi.org/ $10.18564 /$ jasss.4410

Zhang, H., \& Li, Y. (2014). Agent-based simulation of the search behavior in China's resale housing market: Evidence from Beijing. Journal of Artificial Societies and Social Simulation, 17(1), Article 18. https://www.doi. org/10.18564/jasss.2360

Zidar, K., Bartrand, T., Loomis, C., McAfee, C., Geldi, J., Rigall, G., \& Montalto, F. (2017). Maximizing green infrastructure in a Philadelphia neighborhood. Urban Planning, 2(4), 115-132. https://www.doi.org/ 10.17645/up.v2i4.1039

\section{About the Authors}

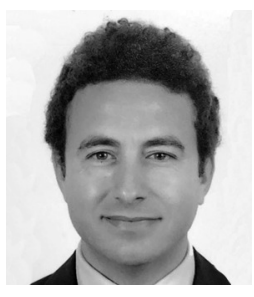

Ali Termos is assistant professor of finance at the American University in Bulgaria (AUBG). Prior to joining AUBG in 2018, Termos was a finance professor at the American University of Beirut (AUB). His research interests and publications are in the area of monetary policy and mortgage lending in the U.S. market. His consulting includes housing policies, housing inequality, and urban dynamics. Recently, Termos' research evolved to study urban development using agent-based models. He earned his PhD in economics from North Carolina State University in 2006.

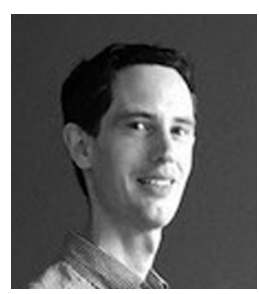

Neil Yorke-Smith is an associate professor of socio-technical algorithmics in the Faculty of Electrical Engineering, Mathematics and Computer Science at the Delft University of Technology, The Netherlands. His research focuses on intelligent decision making in complex socio-technical situations. Yorke-Smith is a senior member of the Association for the Advancement of Artificial Intelligence (AAAI) and of the Association for Computing Machinery (ACM). 